\title{
Monitoring of Ambient Air Particles and Inorganic Elements in China and Korea during an Asian Dust Storm
}

\author{
Eun-Jung Park - Dae-Seon Kim* C Chunghee Park* - Sangwhan Song* - Byunghoon Lee** • \\ Yun-Chul Hong*** - Xiaochuan Pan**** . Jingyu Wang***** \\ Yi-xiang Zhang****** . Kwangsik Park ${ }^{\dagger}$ \\ College of Pharmacy, Dongduk Women's University, Seoul 136-714, Korea \\ *Department of Environmental Health Research, National Institute of Environmental Research, \\ Incheon 404-170, Korea \\ **College of Pharmacy, Seoul National University, Seoul 151-742, Korea \\ ***Seoul National University, College of Medicine, Seoul 110-799, Korea \\ ****Peking University Health Science Center No.38 Xueyuan Road, Haidian District, \\ Beijing 100083, PR China \\ *****Central Laboratory, Peking University School of Public Health, 38 Xue Yuan Road, \\ Beijing 100191, China \\ ******Baotou Medical College, Inner Mongolia University of Science and Technology, \\ Jianshe Road, Donghe District, Baotou, Inner Mongolia 014040, PR China \\ (Received July 26, 2010/Revised September 10, 2010/Accepted October 15, 2010)
}

\begin{abstract}
Concentrations of ambient air particles such as total suspended particulates (TSP), particulate matter (PM) $)_{10}$, and $\mathrm{PM}_{2.5}$, were monitored simultaneously from May to June, 2007, at four locations at Alashan and Beijing in China, and Seoul and Gosan in South Korea. These monitoring sites are in the pathway of Asian dust (AD) storms traveling from China to the Korean peninsula. An AD event was observed in the Korean peninsula on May 25-26. During the sampling period, the average concentrations of TSP and $\mathrm{PM}_{10}$ were each higher than $150 \mu \mathrm{g} / \mathrm{m}^{3}$ in Alashan and Beijing, but not in Seoul and Gosan. The concentration of TSP in Alashan (where the dust storm originated) on the day of the $\mathrm{AD}$ event reached $1824.7 \mu \mathrm{g} / \mathrm{m}^{3}$, this being the highest concentration of air particles observed during the sampling period. The level was decreased to $15 \%$ of this $\left(274.7 \mu \mathrm{g} / \mathrm{m}^{3}\right)$ in Seoul and to $8.7 \%\left(159.0 \mu \mathrm{g} / \mathrm{m}^{3}\right)$ in Gosan when the AD was observed two days later in Korea. Gosan, a representative background site in East Asia, displayed the lowest concentration of particles, with this maximal TSP concentration of $159 \mu \mathrm{g} / \mathrm{m}^{3}$. Inorganic element contents in the air particles were also measured, and the concentrations in the four different regions compared. Concentrations of anthropogenically-enriched heavy metals in $\mathrm{PM}_{10}$ and $\mathrm{PM}_{2.5}$, such as lead, arsenic, cadmium, and mercury, were higher in the metropolitan cities of Beijing and Seoul compared to non-industrialized regions of Alashan and Gosan. However, the concentrations of inorganic soil elements including iron, magnesium, aluminum sodium, and manganese, were higher in Alashan compared to those in other sampling sites.
\end{abstract}

Keywords: asian dust, monitoring, China and Korea, inorganic elements

\section{Introduction}

Asian dust (AD, also called Yellow Sand) storm

Corresponding author: College of Pharmacy, Dongduk

Women's University

Tel: 82-2-940-4522, Fax: 82-2-940-4159

E-mail: kspark@dongduk.ac.kr is a seasonal meteorological phenomenon that sporadically affects East Asia. AD storms originate in the deserts of Mongolia and northern China, traverse east China, and reach the Korean peninsula, Japan, Hawaii, and even California. ${ }^{1,2)}$ Hazardous chemicals appear to be present at relatively low levels in $\mathrm{AD}$ at the origin because 
$\mathrm{AD}$ is derived from alkaline soil or sands. However, AD attracts many different chemicals including gaseous products, heavy metals, and organic compounds when it traverse the region of industrialized eastern China., ${ }^{3,4)}$ Recently, AD storms were found to be increasing in Korea because of rapid desertification in central and northern China and in Mongolia. According to the report of Korea Meteorological Administration (http://www.kma.go.kr), fewer $\mathrm{AD}$ storms per year had occurred before 1990, but this number has risen to 26 events with 47 dusty days of six spring seasons from 1996 to 2001, and more storms occur in the recent years. It is of interest that the ambient particle concentrations present in $\mathrm{AD}$ in Korea have increased. ${ }^{5)}$ In addition, the concentrations of hazardous chemicals such as heavy metals also appear to be on the rise in $\mathrm{AD}$ due to the rapid industrialization.)

Recent epidemiological studies demonstrated that $\mathrm{AD}$ storms are associated with a rise in daily mortality in Seoul, Korea ${ }^{7,8)}$ and in Taipei, Taiwan." $\mathrm{AD}$ increased the frequency of cardiopulmonary emergency visits ${ }^{10,11)}$ and daily stroke admissions ${ }^{12)}$ in Taiwan; it elevated the number of adverse respiratory symptoms and lowered peak expiratory flow in children with mild asthma. ${ }^{13,14)} \mathrm{AD}$ or ambient air particles also increased the incidence of lung inflammation and injury in pulmonary hypertensive rats. ${ }^{15-18)}$

Based on the potential adverse effects of $\mathrm{AD}$ storms on human health, it would be of interest to know the path which an $\mathrm{AD}$ storm take and to know whether this may be correlated with higher health risks in individuals exposed to an $\mathrm{AD}$ storm. In the present study, we tried to compare the concentration of ambient particles and inorganic elements in different sites including the origin of $\mathrm{AD}$, metropolitan cities in China and Korea.

\section{Materials and Methods}

\section{Sampling sites}

Samples were collected at 4 sites (Alashan and Beijing in China, and Seoul and Gosan in Korea) and the locations are shown in Fig. 1. Three-day backward trajectories of $\mathrm{AD}$ arriving at Seoul was

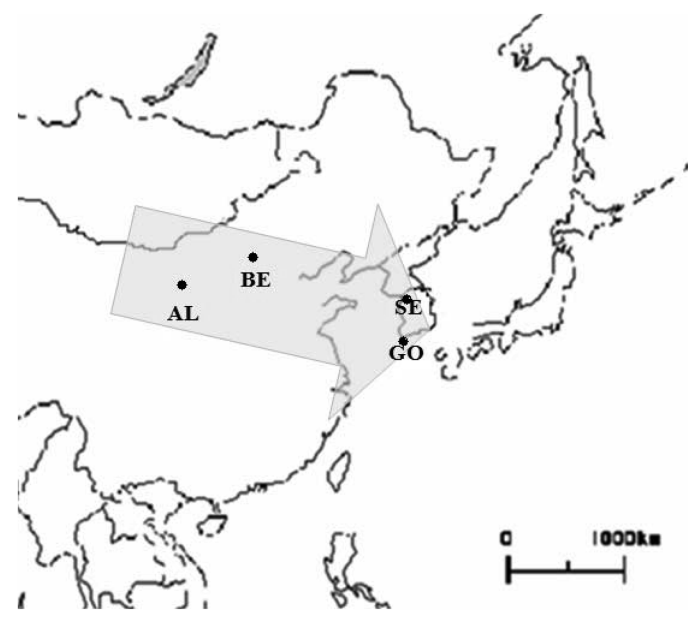

Fig. 1. Locations of sampling sites in China and Korea. AL: Alashan, BE: Beijing, SE: Seoul, GO: Gosan. Asian Dust event was observed on May 23 in Alashan, on May 24 in Beijing, from May 25 to 26 of 2007 in Seoul and Gosan.

previously reported. ${ }^{19)}$ Alashan is a small city in the west of Inner Mongolia, China. The Bardain Jaran Desert, Tengger Desert, and Ulan Buh Desert are close to Alashan County, the districts of which are the main origins of $\mathrm{AD}$ in China. Samplers for TSP, PM10, and PM2.5 were located on top of a hotel on the west edge of Alashan. The sampling site was considered as a background site because no source of anthropogenic air pollution exists on the west side of the city, which is the border of the Tengger Desert. Sampling in Beijing was conducted on the seventh floor (approximately $20 \mathrm{~m}$ high) of a building at Peking University Health Science Center (PKUHSC). The site is near Xueyuan Road, which has heavy traffic in the Haidian District and considered an industrialized location. Sampling in Seoul was conducted on the top of a building at Dongduk Women's University in northern Seoul. Apartment complexes surround this university building, and a 6-lane road is approximately $500 \mathrm{~m}$ from the sampling site. Although there are no official data on the traffic density, it is busy with gasoline-fueled passenger cars and diesel-fueled trucks, natural gas-fueled buses, and motorcycles. No other sources of industrial pollution exist in the vicinity. Samplers at Gosan were set on the ground at a site near the 
Yellow Sea. Gosan is located at the western tip of Jeju Island, Korea $\left(33^{\circ} 17^{\prime} \mathrm{N}, 126^{\circ} 10^{\prime} \mathrm{E}\right.$, and $70 \mathrm{~m}$ Above Sea Level, ASL). It is a small village; at the end of 2006 with a population of 4,000. It is a typical rural area of Jeju Island without any industry or other pollution sources. Gosan is a representative background site in East Asia and has served as a major research location for the long-range transport of ambient air in north-east Asia. ${ }^{1,4)}$

Sampling was conducted once a day for $20 \mathrm{hrs}$ from May 14 to June 15, 2007 in Alashan, May 17 to June 18 in Beijing, May 8 to June 15 in Seoul, and May 15 to June 18 in Gosan. During the sampling period, AD storm was observed on May 23 in Alashan, on May 24 in Beijing, and on May 25-26 in Seoul and Gosan, Korea. The AD originated in Alashan on May 23, traversed Beijing, and moved to Seoul and Gosan. Meteorological data are shown in Table 1. Three sets of mediumvolume air samplers (TH-150 Sampler, Wuhan Tianhong Intelligence Instrumentation Facility, Beijing, China) for TSP, PM10, and PM2.5 were used for collecting the ambient particulate matter (PM) with $10 \mathrm{~cm}$ quartz membrane filters (Pal, NY, USA). Samples were collected regularly for $20 \mathrm{hrs} /$ day, from 10:00 a.m. to 6:00 a.m. of the following day. During the break time of $4 \mathrm{hrs}$, filters were exchanged. Air flow was set at $100 \mathrm{~L} /$ min. After sampling, filters were kept in a desiccator for at least three days to reduce the humidity of the samples, and then the samples were weighed. The sample weight was divided by air volume adjusted to the standardized air condition $\left(20^{\circ} \mathrm{C}, 1 \mathrm{~atm}\right)$.

\section{Chemical analysis}

For the chemical analysis of inorganic elements in the ambient air particles collected from the 4 different sites, part of each sampling filter (1/8 filter) was cut out and immersed in a mixed acid of $5 \% \mathrm{HNO}_{3}(5 \mathrm{~m} l)$ and $15 \% \mathrm{HNO}_{3}(2 \mathrm{ml})$ respectively, then diluted up to $10 \mathrm{~m} l$ with $1 \%$ $\mathrm{HNO}_{3}$. Filters were immersed overnight at room temperature, and then extracted with a temperaturecontrolled electrical heater. After acid extraction of the sampling filters, inorganic elements were measured by AFS230E hydride-activating atomic fluorescence spectrophotometer (AFS) (Beijing Haiguang Instrument Co., Beijing, China), AA2610 atomic absorption spectrophotometer (AAS) (Beijing Chaoyang Huayang Pphotic Instrument Co., Beijing, China), and Elan DRC type-II electricityinduced coupling plasma mass-spectrograph (PerkinElmer Sciex Co., Waltham, MA, USA). Detection limits (ng/L) are as follows: Al: 90, Cr: 2, Mn: 3, Fe: 900, Ni: 5, Cu: 30, Zn: 60, Cd: 3, Pb: 12, As: 40, Na: 2,000, Mg: 2,000, K: 2,000, Hg: 4, and

Table 1. Meteorological data of sampling sites during AD storms

\begin{tabular}{llcccccc}
\hline \hline & & May 22 & May 23 & May 24 & May 25 & May 26 & May 27 \\
\hline \multirow{3}{*}{$\mathrm{AL}$} & Temp. $\left({ }^{\circ} \mathrm{C}\right)$ & 17.4 & 12.6 & 16.6 & 20.0 & 20.9 & 21.3 \\
& RH $(\%)$ & 48 & 35 & 21 & 19 & 15 & 11 \\
& Rainfall $(\mathrm{mm})$ & 0 & 0 & 0 & 0 & 0 & 0 \\
\hline \multirow{3}{*}{$\mathrm{BE}$} & Temp. $\left({ }^{\circ} \mathrm{C}\right)$ & 17.8 & 19.2 & 23.8 & 24.3 & 26.2 & 25.5 \\
& RH $(\%)$ & 78 & 88 & 41 & 25 & 35 & 30 \\
& Rainfall $(\mathrm{mm})$ & 33.4 & 9.4 & 0 & 0 & 0 & 0 \\
\hline \multirow{3}{*}{$\mathrm{SE}$} & Temp. $\left({ }^{\circ} \mathrm{C}\right)$ & 19.7 & 20.7 & 19.8 & 19.7 & 20.3 & 22.5 \\
& RH $(\%)$ & 47.8 & 48.9 & 78.4 & 71.6 & 50.3 & 52.0 \\
& Rainfall $(\mathrm{mm})$ & 0 & 0 & 49.0 & 1.0 & 0 & 0 \\
\hline \multirow{3}{*}{$\mathrm{GO}$} & Temp. $\left({ }^{\circ} \mathrm{C}\right)$ & 18.7 & 20.8 & 20.3 & 17.1 & 20.2 & 20.2 \\
& RH $(\%)$ & 58.4 & 72.4 & 89.9 & 92.5 & 74.0 & 65.5 \\
& Rainfall $(\mathrm{mm})$ & 0 & 0 & 14.0 & 2.5 & 0 & 0 \\
\hline
\end{tabular}

Asian Dust storm was observed on May 23 in Alashan (AL), on May 24 in Beijing (BE), from May 25 to 26 of 2007 in Seoul (SE) and Gosan (GO). RH; Relative humidity. 
Ca: 500. Quality assurance was conducted by an external expert and no specific issues were found.

\section{Statistical analysis}

Regression analysis was performed using SPSS (Statistical Package for Social Sciences) for the correlation study of PM 10 and inorganic elements.

\section{Results}

During the sampling period, the concentrations of TSP, PM10, and PM2.5 were highest in Alashan among the 4 sampling sites (Table 2). The average daily concentration of TSP was 514.5 $\mu \mathrm{g} / \mathrm{m}^{3}$ and reached $1,824.7 \mu \mathrm{g} / \mathrm{m}^{3}$ on May 23, 2007 when an AD storm occurred in the Alashan region. The average daily concentrations of PM10 and PM2.5 in Alashan were 361.7 and $177.6 \mu \mathrm{g} /$ $\mathrm{m}^{3}$, respectively. The distribution of PM is shown in Table 2, and it was used to calculate the distribution of particle fraction to TSP. The distribution ranged from $63-70 \%$ in the case of PM10 and from $290-36 \%$ in the case of PM2.5 at the 4 sampling sites. The PM2.5 ratio to PM10 ranged from $45-57 \%$. The ratio of PM2.5/TSP in Alashan was $34.5 \%$, which indicates that PM2.5 is also a main component of AD.

The concentrations of inorganic elements are shown in Table 3 for PM2.5 and Table 4 for
PM10. In Beijing, concentrations of toxic heavy metals, such as lead $(\mathrm{Pb})$, arsenic (As), and cadmium $(\mathrm{Cd})$ in PM2.5 were higher than in Alashan or in Seoul. In the case of the $\mathrm{Pb}$ level in PM10, the average daily concentration in Beijing reached $240.6 \mathrm{ng} / \mathrm{m}^{3}$, which is approximately 5fold higher than that in Alashan. The concentration pattern of inorganic elements in PM2.5 among the 4 sampling sites was similar to that of PM10. The mean concentrations of chromium (Cr) or nickel (Ni) in Alashan were higher than thoses in other cities (Table 3 and Table 4). The concentrations of inorganic elements that may originate from soil sources such as iron $(\mathrm{Fe})$, aluminum $(\mathrm{Al})$, magnesium $(\mathrm{Mg})$, manganese $(\mathrm{Mn})$, and sodium $(\mathrm{Na})$ were higher in Alashan than those of in Beijing or Seoul. The increased levels of soil-originated elements were attributable to elevated amounts of PM. Based upon regressional analysis, the concentrations of anthropogenically enriched elements, such as $\mathrm{Pb}, \mathrm{As}$, and $\mathrm{Cd}$ were not correlated with the concentration of PM10. The correlation coefficiency $\left(\mathrm{R}^{2}\right)$ was 0.041 of $\mathrm{Pb}, 0.004$ of $\mathrm{As}$, and 0.028 of $\mathrm{Cd}$. However, the concentrations of possible soil-originated elements, such as $\mathrm{Fe}\left(\mathrm{R}^{2}=\right.$ 0.783), $\mathrm{Al}\left(\mathrm{R}^{2}=0.717\right), \mathrm{Mg}\left(\mathrm{R}^{2}=0.689\right)$, were significantly correlated with the concentration of PM10. The correlation coefficiencies of $\mathrm{Mn}$ and $\mathrm{Na}$ were relatively low compared to other soil-

Table 2. Concentrations of TSP, PM10, and PM2.5

\begin{tabular}{|c|c|c|c|c|c|c|c|}
\hline & & Mean \pm SD & Min. & $25 \%$ tile & $50 \%$ tile & $75 \%$ tile & Max. \\
\hline \multirow{4}{*}{ TSP } & $\mathrm{AL}$ & $514.5 \pm 399.4$ & 135.0 & 269.1 & 381.8 & 606.5 & 1824.7 \\
\hline & $\mathrm{BE}$ & $330.5 \pm 139.6$ & 109.5 & 267.9 & 306.2 & 373.1 & 833.6 \\
\hline & $\mathrm{SE}$ & $99.8 \pm 65.2$ & 30.0 & 51.7 & 78.2 & 135.0 & 293.2 \\
\hline & GO & $51.0 \pm 34.1$ & 15.9 & 28.0 & 46.1 & 59.7 & 159.0 \\
\hline \multirow{4}{*}{ PM10 } & $\mathrm{AL}$ & $361.7 \pm 249.4$ & 115.8 & 184.0 & 281.6 & 454.3 & 1080.0 \\
\hline & $\mathrm{BE}$ & $223.1 \pm 114.1$ & 53.7 & 159.4 & 205.7 & 260.0 & 632.3 \\
\hline & $\mathrm{SE}$ & $63.6 \pm 45.0$ & 19.1 & 30.9 & 50.4 & 75.5 & 192.7 \\
\hline & GO & $32.5 \pm 22.2$ & 11.1 & 19.5 & 24.7 & 37.7 & 92.7 \\
\hline \multirow{4}{*}{ PM2.5 } & $\mathrm{AL}$ & $177.6 \pm 122.6$ & 29.6 & 89.4 & 129.5 & 250.2 & 530.1 \\
\hline & $\mathrm{BE}$ & $106.6 \pm 57.9$ & 33.9 & 63.1 & 92.1 & 128.5 & 271.5 \\
\hline & $\mathrm{SE}$ & $36.4 \pm 25.2$ & 11.4 & 19.0 & 26.0 & 44.9 & 113.7 \\
\hline & GO & $14.9 \pm 7.7$ & 8.6 & 10.8 & 12.8 & 15.4 & 45.9 \\
\hline
\end{tabular}

AL; Alashan, BE; Beijing, SE; Seoul, and GO; Gosan. 


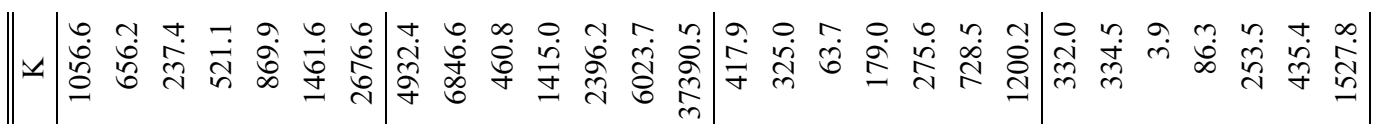
Z

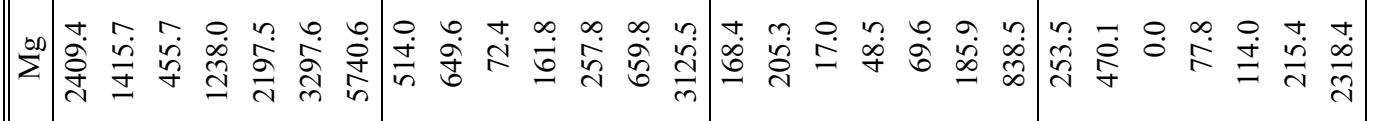

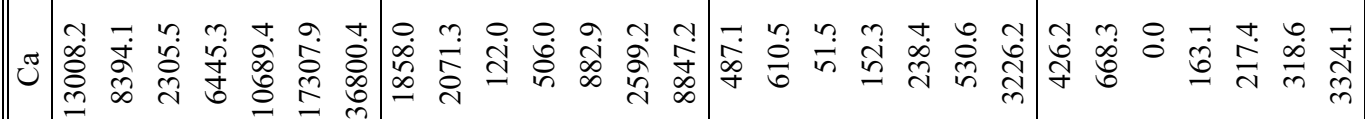

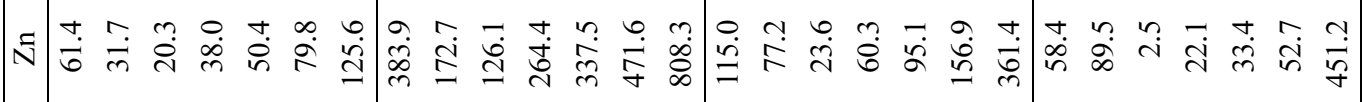

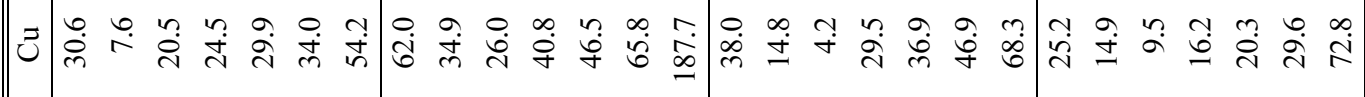

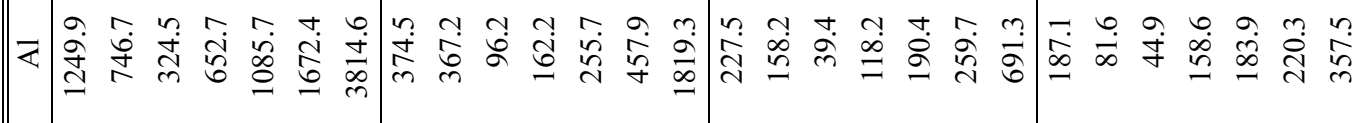

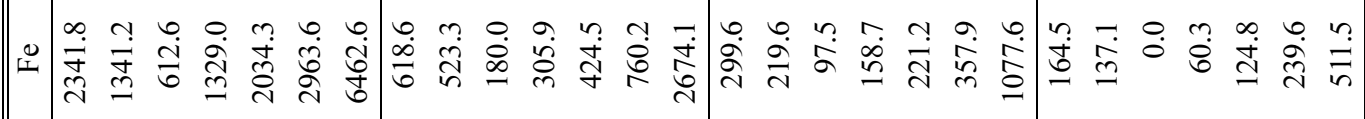

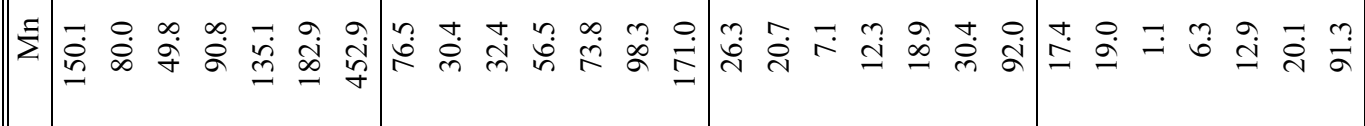

य)

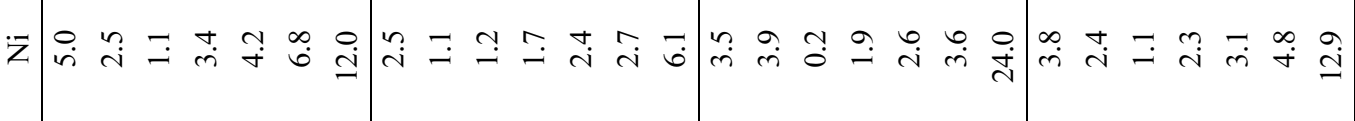

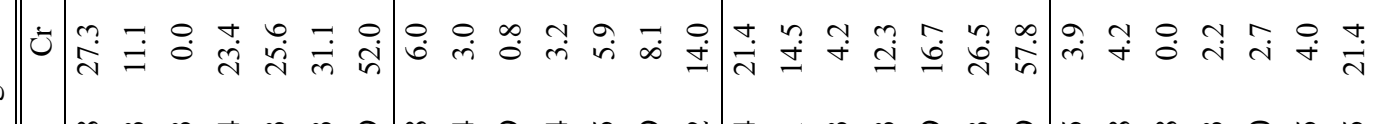
高

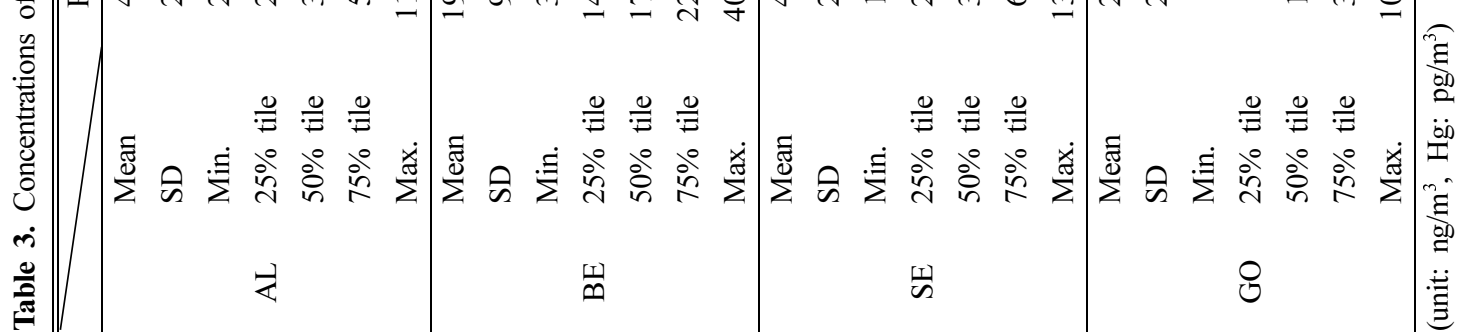




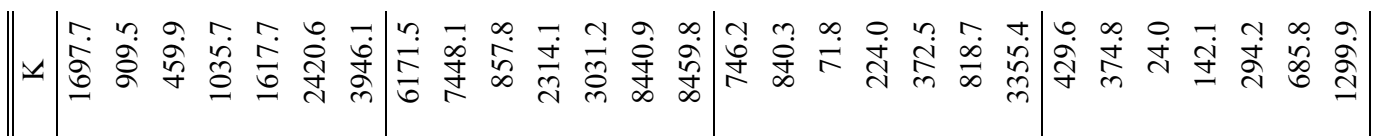

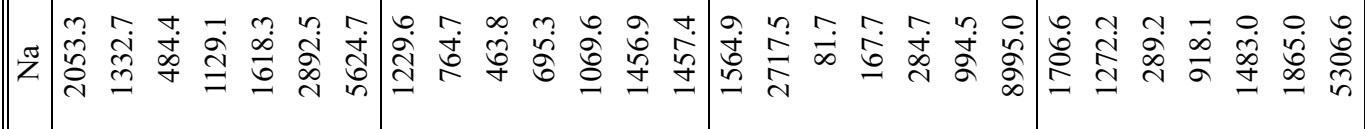

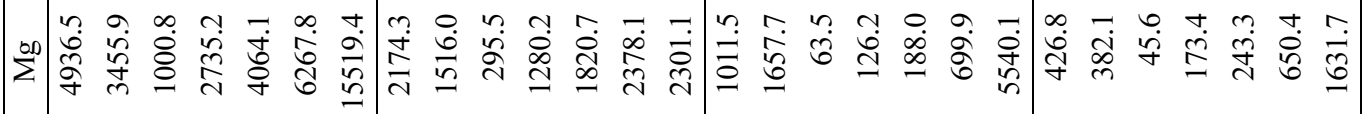

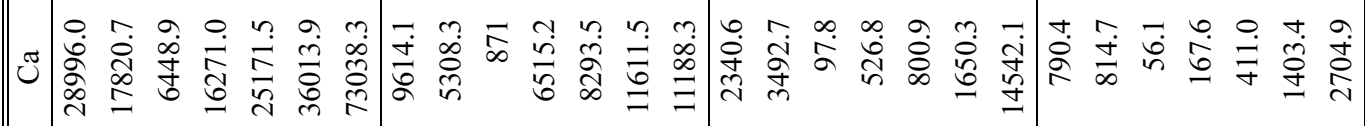

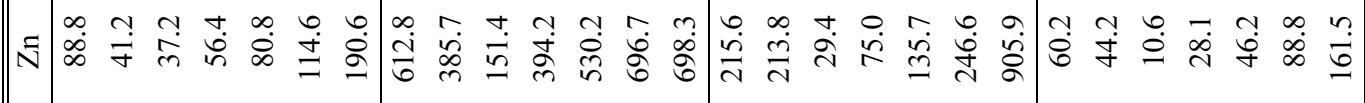

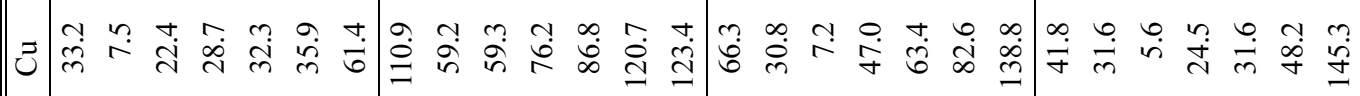

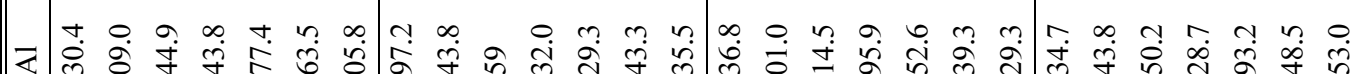

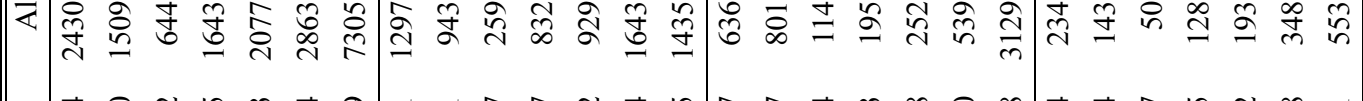

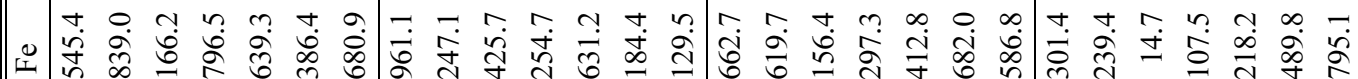

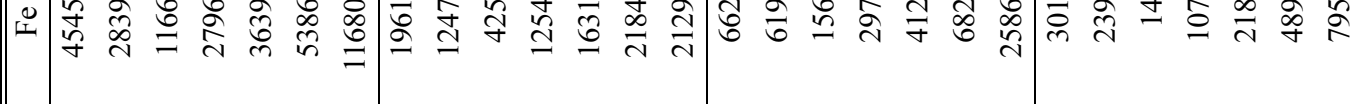

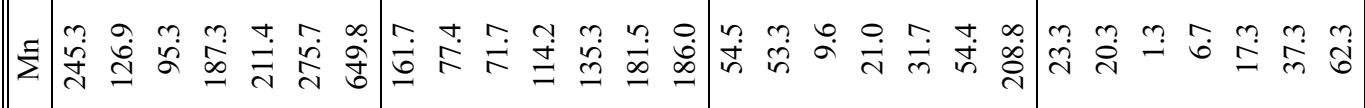



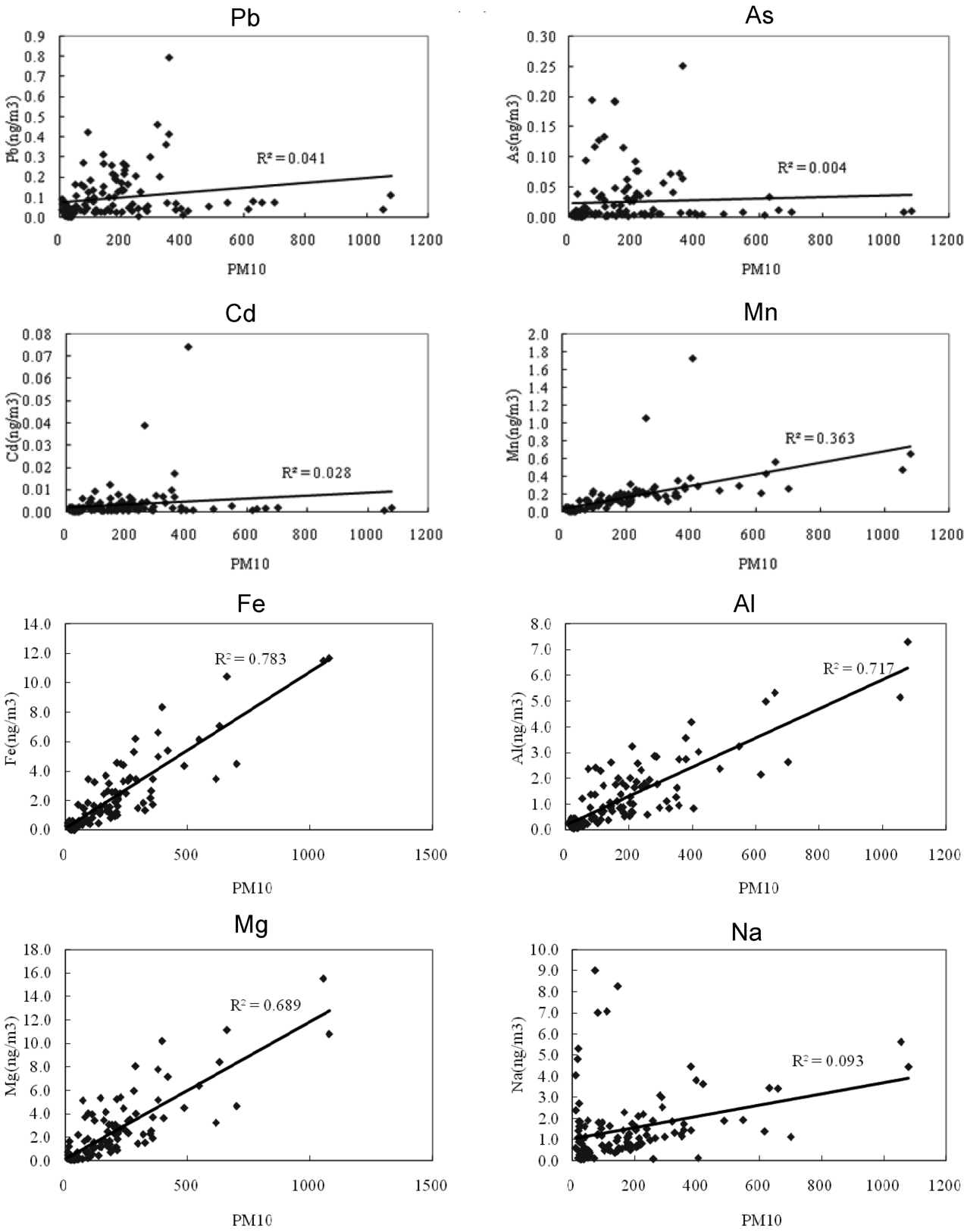

Fig. 2. Regression analysis for the correlations of PM10 and inorganic elements.

The continuous lines represent the regression lines. Total number of PM10 samples in this analysis was 123, which collected from Alashan, Beijing, Seoul and Gosan during the sampling period.

originated elements. The R-square values of $\mathrm{Fe}$ and $\mathrm{Al}$ were very high when they were compared to those of other elements, which seemed to be indicators of soil concentration in ambient air
(Fig. 2) The same pattern was also shown in PM2.5 using regression analysis (data not shown).

During the approximate 30 days of sampling period from May to June, an AD storm occurred 
in Seoul and Gosan from May 25 to May 26. The $\mathrm{AD}$ originated in Alashan on May 23, traversed Beijing on May 24, and arrived in Seoul and Gosan on the afternoon of May 25, lasting to the morning of May 26. Before and after the AD storm, ambient particle concentrations of TSP, PM10, and PM2.5 at 4 sampling sites are shown in Table 5. The TSP concentration on May 23 was $1824.7 \mu \mathrm{g} / \mathrm{m}^{3}$ in Alashan, $144.4 \mu \mathrm{g} / \mathrm{m}^{3}$ in Beijing, $86.2 \mu \mathrm{g} / \mathrm{m}^{3}$ in Seoul, and $39.1 \mu \mathrm{g} / \mathrm{m}^{3}$ in Gosan. Exceedingly high concentrations of TSP in Alashan on May 23 revealed that the $\mathrm{AD}$ event occurred in Alashan. On May 24, TSP concentration in Alashan significantly decreased to $483.6 \mu \mathrm{g} / \mathrm{m}^{3}$, but TSP concentration in Beijing rose to $833.6 \mu \mathrm{g} / \mathrm{m}^{3}$, which indicated that the $\mathrm{AD}$ storm travelled from Alashan to Beijing. Particle concentrations in Seoul and Gosan were not measured on May 24 due to rain. In the afternoon of May 25, AD was observed on the Korean peninsula, such that the concentrations of TSP in Seoul and Gosan increased markedly to 274.7 and $159 \mu \mathrm{g} / \mathrm{m}^{3}$, respectively. The AD storm occurred in the afternoon in Korea and lasted until the morning of May 26. As shown in Table 5, PM2.5 which belongs to the class of fine particles, also increased during the $\mathrm{AD}$ event on May 23 in Alashan, on May 24 in Beijing, and from May 25 to May 26 in Seoul and Gosan. When we compared the concentrations of anthropogenically enriched heavy metals along the sampling sites data demonstrated that the concentration of anthropogenically enriched elements were higher in the metropolitan areas. As shown in Table 6, in which anthropogenic elements and natural soil element were compared, the concentrations of As, $\mathrm{Pb}$, and $\mathrm{Cd}$ in PM10 and PM2.5 were always higher in Beijing and Seoul than those in Alashan and Gosan during the $\mathrm{AD}$ storm. The Alashan PM10 level was $1,824.7 \mu \mathrm{g} / \mathrm{m}^{3}$ on May 23 when the $\mathrm{AD}$ event was observed. The Beijing PM10 level was $144.4 \mu \mathrm{g} / \mathrm{m}^{3}$ on May 23 when the $\mathrm{AD}$ event was not observed. The PM 10 level in Alashan was 12.6-fold higher than in Beijing (Table 5). However, the As levels were $8 \mathrm{ng} / \mathrm{m}^{3}$ in Alashan and $32.9 \mathrm{ng} / \mathrm{m}^{3}$ in Beijing (Table 6). When the As concentration was calculated by weight of the particles, it was found that it was approximately $4.4 \mathrm{ng} / \mathrm{mg}$-particle in Alashan, but $235 \mathrm{ng} / \mathrm{mg}$-particle in Beijing. Results indicate that concentration of As in PM10 collected in Beijing was 53-fold higher than in Alashan. The concentrations of the inorganic compounds $\mathrm{Al}$, $\mathrm{Mg}, \mathrm{Na}, \mathrm{Mn}$, and $\mathrm{Fe}$ in PM10 and PM2.5 increased with the elevated levels of particle concentrations during the $\mathrm{AD}$ storm (Tables 5 and 6).

Table 5. Concentrations of ambient air particles during an $\mathrm{AD}$ storm

\begin{tabular}{|c|c|c|c|c|c|c|c|}
\hline & & May 22 & May 23 & May 24 & May 25 & May 26 & May 27 \\
\hline \multirow{4}{*}{ TSP } & $\mathrm{AL}$ & 748.5 & 1824.7 & 483.2 & 156.9 & 234.7 & 160.1 \\
\hline & $\mathrm{BE}$ & 109.5 & 144.4 & 833.6 & 300.7 & 401.1 & 312.1 \\
\hline & $\mathrm{SE}$ & 83.7 & 86.2 & - & 274.7 & 203.0 & 172.0 \\
\hline & $\mathrm{GO}$ & 26.6 & 39.1 & - & 159.0 & 131.8 & 105.0 \\
\hline \multirow{4}{*}{ PM10 } & $\mathrm{AL}$ & 397.8 & 1055.4 & 287.5 & 118.9 & 205.8 & 121.0 \\
\hline & $\mathrm{BE}$ & 103.1 & 96.3 & 632.3 & 211.7 & 250.5 & 224.7 \\
\hline & SE & 49.9 & 56.9 & - & 192.7 & 163.7 & 142.5 \\
\hline & GO & 18.9 & 27.8 & - & 84.6 & 92.7 & 82.8 \\
\hline \multirow{4}{*}{ PM2.5 } & $\mathrm{AL}$ & 120.6 & 323.3 & 62.0 & 29.6 & 81.1 & 55.9 \\
\hline & $\mathrm{BE}$ & 96.1 & 33.9 & 153.8 & 76.3 & 82.1 & 55.0 \\
\hline & $\mathrm{SE}$ & 19.0 & 37.2 & - & 65.8 & 113.7 & 100.6 \\
\hline & GO & 10.4 & 20.4 & - & 24.1 & 45.9 & 23.9 \\
\hline
\end{tabular}

(unit: $\mu \mathrm{g} / \mathrm{m}^{3}$ )

Asian Dust storm was observed on May 23 in Alashan, on May 24 in Beijing, from May 25 to 26 of 2007 in Seoul and Gosan. "_." ; sampling was not done due to rain. 


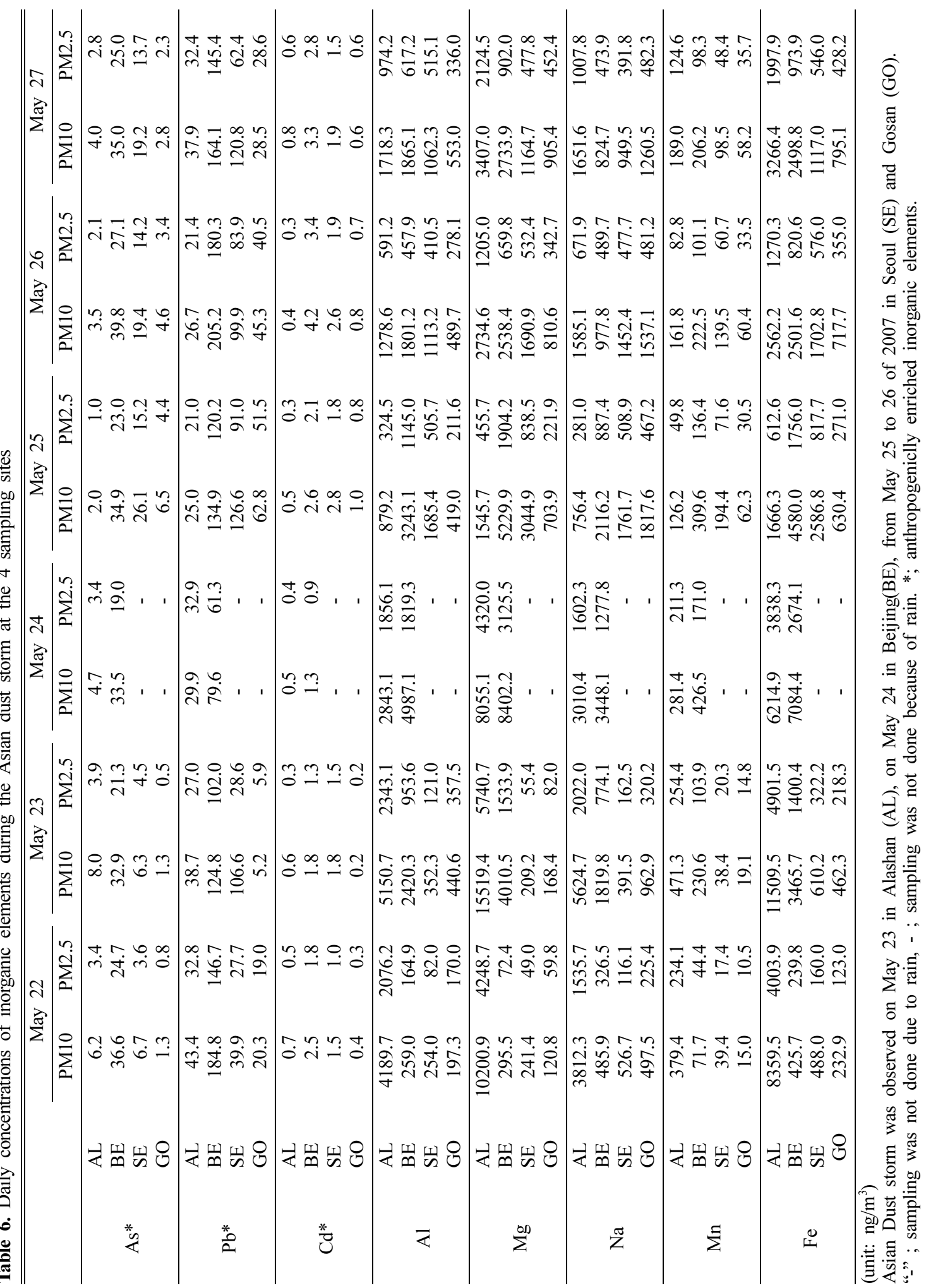




\section{Discussion}

The concentrations of TSP, PM10, or PM2.5 in Alashan were markedly higher compared with those in other cities. ${ }^{20-22)}$ It is interesting to note that the ratio of PM2.5/TSP in Alashan was not significantly different from those of Beijing or Seoul because it has been known that distribution of PM2.5 is relatively low in non-polluted areas. ${ }^{23)}$ PM2.5 collected in Alashan did not originate from anthropogenic sources but from natural soil. However, PM2.5 distribution during the $\mathrm{AD}$ in Alashan may be higher than expected based on the ratio of PM2.5/TSP.

Daily PM10 concentrations of Beijing exceeded $150 \mu \mathrm{g} / \mathrm{m}^{3}$, which is the current National Ambient Air Quality Standard (NAAQS) of the U.S. Environmental Protection Agency (EPA). During the 32 days of the sampling period, the daily PM10 concentration in Beijing exceeded the NAAQS for 27 days. During the 36 days of sampling, the daily PM 10 concentration exceeded NAAQS for only 2 days in Seoul. The 24-hr average of NAAQS for PM2.5 in the 1997standards of the U.S. EPA was $65 \mu \mathrm{g} / \mathrm{m}^{3}$, but was changed to $35 \mu \mathrm{g} / \mathrm{m}^{3}$ in the EPA's 2006-standard. All days except one in Alashan, and two in Beijing exceeded the 2006 NAAQS for PM2.5. In Seoul, $35 \%$ of the sampling days exceeded the PM2.5 standards. However, only one day exceeded the PM2.5 standard in Gosan, which was the day of the $\mathrm{AD}$ event. Chuersuwan et al. $^{24)}$ reported measuring the ambient particle concentrations of the Bangkok Metropolitan Region (BMR) during 2002-2003. According to this study, average daily concentrations of PM10 and PM2.5 at the traffic site were $108.1 \pm 35.5 \mu \mathrm{g} / \mathrm{m}^{3}$ and $69.0 \pm 28.8 \mu \mathrm{g} / \mathrm{m}^{3}$, respectively. Particle concentrations in Beijing in 2007 were 2-fold higher than those of the BMR in 2003. Compared with the cities of Europe, Beijing showed higher concentrations of ambient PM. ${ }^{25,26)}$

In general, the concentrations of inorganic elements in PM were increased as the increase of concentration of PM10 or PM2.5. ${ }^{27-29)}$ However, there was a regional difference in concentrations of anthropogenic metals. When the concentrations were compared among the 4 sampling sites, the concentrations of possible anthropogenically enriched elements, such as $\mathrm{Pb}, \mathrm{Cd}, \mathrm{Hg}, \mathrm{As}, \mathrm{Cu}$, and $\mathrm{Zn}$, were higher in the metropolitan cities of Beijing and Seoul compared to Alashan (Table 4). As indicated previously, particle concentrations of PM10 and PM2.5 in Alashan were higher than those in other sampling sites, but total concentrations of anthropogenically enriched elements were greater in Beijing or Seoul than in Alashan. Data thus indicate that there are many sources of environmental pollution in metropolitan cities. The mean concentration of $\mathrm{Cr}$ or $\mathrm{Ni}$ was greater in Alashan than Beijing or Seoul. Previous reports suggested that $\mathrm{Cr}$ and $\mathrm{Ni}$ reflect soil sources ${ }^{3)}$. However, when the metal concentrations were calculated by particle mass (ng metal/mg weight of particle), not by total ambient air volume, the concentrations of $\mathrm{Cr}$ and $\mathrm{Ni}$ were higher in Beijing and Seoul compared to Alashan. It seems that $\mathrm{Cr}$ or $\mathrm{Ni}$ released from industrial sources or other environmental pollution sources was also attached to the particles in the metropolitan cities of Beijing or Seoul. The concentration of soil originated inorganic compounds such as $\mathrm{Al}, \mathrm{Mg}, \mathrm{Na}, \mathrm{Mn}$ and $\mathrm{Fe}$ was elevated on the day of $\mathrm{AD}$ and well represented the change of particle concentration. However, it seemed that the anthropogenic compound including $\mathrm{As}, \mathrm{Pb}$ and $\mathrm{Cd}$ did not always represent the particle concentration (Table 6).

A recent study on the source identification of metals included size-fractionated airborne PM suggests that high loadings on $\mathrm{Fe}, \mathrm{Mn}$, and $\mathrm{Cr}$ reflect soil sources. ${ }^{30)}$ Particles collected in central Taiwan during an AD event in the spring of 2000 also showed a high loading of the crustal elements $\mathrm{Ca}, \mathrm{Mg}, \mathrm{Al}$, and $\mathrm{Fe}^{31)}$ The samples collected in Alashan displayed the highest concentration of soil-derived inorganic elements ${ }^{32,3)}$ and may be indicators of an AD storm, as shown in Table 4. The changes of the particle concentration of PM10 and PM2.5 were almost the same as those of TSP at the sampling sites. Several reports also indicated that PM2.5 increased during AD storms..$^{33-35)}$

In summary, $\mathrm{AD}$ storm originating in Alashan attracts anthropogenically enriched heavy metals as the storm traverses the region of industrialized eastern China. PM2.5 as well as PM10 and TSP, is predominant components of $\mathrm{AD}$ which originate in Alashan as reflected by the ratio of PM2.5/TSP. 
The hazardous heavy metals in AD were highter in metropolitan area, Beijing and Seoul than those in Alashan and Gosan.

\section{Conclusion}

The concentrations of the ambient particles TSP, PM10, and PM2.5 were monitored simultaneously at four different locations on the $\mathrm{AD}$ pathway: Alashan and Beijing in China, Seoul and Gosan in Korea. Sampling was done from May to June 2007 for about 30 days and an AD event was observed during the period. Inorganic elements, including hazardous heavy metals, were also measured in the collected particles to know the changes of metal concentrations, when the $\mathrm{AD}$ passed over metropolitan cities.

1. During the sampling period in Alashan and Beijing, the average particle concentrations of TSP, and PM10 were higher than $150 \mu \mathrm{g} / \mathrm{m}^{3}$, but not in Seoul and Gosan. The concentration of TSP in Alashan on the day of AD event reached 1824.7 $\mu \mathrm{g} / \mathrm{m}^{3}$. The level was decreased to $15 \%(274.7 \mu \mathrm{g} /$ $\left.\mathrm{m}^{3}\right)$ in Seoul and $8.7 \%\left(159.0 \mu \mathrm{g} / \mathrm{m}^{3}\right)$ in Gosan when the $\mathrm{AD}$ was observed in two days later in the Korean peninsula.

2. The concentrations of anthropogenic compounds, such as $\mathrm{Pb}, \mathrm{Cd}, \mathrm{Hg}, \mathrm{As}, \mathrm{Cu}$, and $\mathrm{Zn}$, were higher in the metropolitan cities of Beijing and Seoul than those in Alashan and Gosan. The concentrations of inorganic elements which may originate from soil sources such as $\mathrm{Fe}, \mathrm{Al}, \mathrm{Ca}, \mathrm{Mg}$, and $\mathrm{Na}$, were higher in Alashan than those in Beijing or Seoul.

3. When we compared the concentrations of anthropogenic heavy metals along the sampling sites from Alashan to Beijing and then to Seoul and Gosan, it was found that the anthropogenic elements $(\mathrm{Pb}, \mathrm{As}, \mathrm{Cd})$ were not correlated with the $\mathrm{AD}$ concentration by regressional analysis. However, the concentrations of inorganic elements $\mathrm{Al}, \mathrm{Mg}$, and Fe bound to PM10 and PM2.5 were correlated with the concentrations of PM10 and PM2.5 during the $\mathrm{AD}$ event.

4. The fractional distribution of $\mathrm{AD}$ originated in Alashan in May was as follows: PM10/TSP 63\%70\%, PM2.5/TSP 30\%-34\%, and PM2.5/PM10 $46 \%-57 \%$, which means that fine particles are also major component of $\mathrm{AD}$ originated in the Alashan region.

\section{Acknowledgement}

This study was supported by National Institute of Environmental Research.

\section{References}

1. Han, Y., Fang, S., Zhao, T. and Kang, S. : Long range trans-pacific transport and deposition of Asian dust aerosols. Journal of Environmental Science (China), 20, 424-428, 2008.

2. Kim, W., Doh, S. J., Yu, Y. and Lee, M. : Role of Chinese wind-blown dust in enhancing environmental pollution in metropolitan Seoul. Environmental Pollution, 153, 333-341, 2008.

3. Lee, B. K., Lee, H. K. and Jun, N. : Analysis of regional and temporal characteristics of PM10 during an Asian dust episode in Korea. Chemosphere, 63, 1106-1115, 2006.

4. Moon, K. J., Han, J. S., Ghim, Y. S. and Kim, Y. J. : Source apportionment of fine carbonaceous particles by positive matrix factorization at Gosan background site in East Asia. Environment International, 34, 654-664, 2008.

5. Kim, Y. K., Song, S. K., Lee, H. W., Kim, C. H., Oh. I. B., Moon, Y. S. and Shon, Z. H. : Characteristics of Asian dust transport based on synoptic meteorological analysis over Korea. Journal of the Air \& Waste Management Association, 56, 306-316, 2006.

6. Park, S. S., Kim, Y. J., Cho, S. Y. and Kim, S. J. : Characterization of PM2.5 aerosols dominated by local pollution and Asian dust observed at an urban site in Korea during aerosol characterization experiments (ACE)--Asia Project. Journal of the Air \& Waste Management Association, 57, 434443, 2007.

7. Kwon, H. J., Cho, S. H., Chun, Y., Lagarde, F. and Pershagen, G. : Effects of the Asian dust events on daily mortality in Seoul, Korea. Environmental Research, 90, 1-5, 2002.

8. Lee, J. T., Son, J. Y. and Cho, Y. S. : A comparison of mortality related to urban air particles between periods with Asian dust days and without Asian dust days in Seoul, Korea, 2000-2004. Environmental Reearch, 105, 409-413, 2007.

9. Chen, Y., Sheen, P., Chen, E., Liu, Y., Wu, T. and Yang, C. : Effects of Asian dust storm events on daily mortality in Taipei, Taiwan. Environmental Research, 95, 151-155, 2004.

10. Chan, C., Chuang, K., Chen, W., Chang, W., Lee, C. and Peng, C. : Increasing cardiopulmonary emergency visits by long-range transported Asian 
dust storms in Taiwan. Environmental Research, 106, 393-400, 2008.

11. Yang, C. Y., Cheng, M. H. and Chen, C. C. : Effects of Asian dust storm events on hospital admissions for congestive heart failure in Taipei, Taiwan. Journal of Toxicology and Environmental Health A 72, 324-328, 2009.

12. Yang, C., Chen, Y., Chiu, H. and Goggins, W. B. : Effects of Asian dust storm events on daily stroke admissions in Taipei, Taiwan. Environmental Research, 99, 79-84, 2005.

13. Park, J. W., Lim, Y. H., Kyung, S. Y., An, C. H., Lee, S. P., Jeong, S. H. and Ju, Y. : Effects of ambient particulate matter on peak expiratory flow rates and respiratory symptoms of asthmatics during Asian dust periods in Korea. Respirology, 10, 470-476, 2005.

14. Yoo, Y., Choung, T., Yu, J., Kim, D. K. and Koh, Y. Y. : Acute effects of Asian dust events on respiratory symptoms and peak expiratory flow in children with mild asthma. Journal of Korean, Medical Science, 23, 66-71, 2008.

15. Lei, Y., Chan, C., Wang, P., Lee, C. and Chen, T. : Effects of Asian dust event particles on inflammation markers in peripheral blood and bronchial alveolar lavage in pulmonary hypertensive rats. Environmental Research, 95, 71-76, 2004.

16. Hyoshi, K., Ichinose, T., Sadakane, K., Takano, H., Nishikawa, M., Mori, I., Yanagisawa, R., Yoshida, S., Kumagai, Y., Tomura, S. and Shibamoto, Y. : Asian sand dust enhanced ovalbumin-induced eosinophil recruitment in the alveoli and airway of mice. Environmental Research, 99, 361-368, 2005.

17. Alberg, T., Cassee, F. R., Groeng, E. C., Dybing, E. and Løvik, M.: Fine ambient particles from various sites in Europe exerted a greater IgE adjuvant effect than coarse ambient particles in a mouse model. Journal of Toxicology and Environmental Health $A$ 72, 1-13, 2009.

18. Sawyer, K., Mundandhara, S., Ghio, A. J. and Madden, M. C. : The effects of ambient particulate matter on human alveolar macrophage oxidative and inflammatory responses. Journal of Toxicology and Environmental Health A, 73, 41-57, 2010.

19. Hong, Y. C., Pan, X. C., Kim, S. Y., Park, K., Park, E. J., Jin, X., Yi, S. M., Kim, Y. H., Park, C. H., Song, S. and Kim, H. : Asian dust storm and pulmonary function of school children in Seoul. Science of the Total Environment 408, 754-759, 2010.

20. Lopez, J. M., Callen, M. S., Murillo, R., Carcia, T., Navarro, M. V., Cruz, M. T. and Mastral, A. M. : Levels of selected metals in ambient air PM10 in an urban site of Zaragoza (Spain). Environmental Research, 99, 58-67, 2005.

21. Gilli, G., Traversi, D., Rovere, R., Pignata, C. and Schiliro, T. : Airborne particulate matter: Ionic species role in different Italian sites. Environmental
Research, 103, 1-8, 2007.

22. Park, E., Kim, D. and Park, K. : Monitoring of ambient particles and heavy metals in a residential area of Seoul, Korea. Environmental Monitoring and Assessment, 137, 441-449, 2008.

23. Kavouras, I. G., Koutrakis, P., Cereceda-Balic, F. and Oyola, P. : Source apportionment of PM10 and PM2.5 in five Chilean cities using factor analysis. Journal of the Air \& Waste Management Association, 51, 451-464, 2001.

24. Chuersuwan, N., Nimrat, S., Lekphet, S. and Kerdkumrai, T. : Levels and major sources of PM2.5 and PM10 in Bangkok metropolitan region. Environment International, 34, 671-677, 2008.

25. Tsitouridou, R., Voutsa, D. and Kouimtzis, T. : Ionic composition of PM10 in the area of Thessaloniki, Greece. Chemosphere, 52, 883-891, 2003.

26. Xie, S., Yu, T., Zhang, Y., Zeng, L., Qi, L. and Tang, X. : Characteristics of PM10, $\mathrm{SO}_{2}, \mathrm{NOx}, \mathrm{O}_{3}$ in ambient air during the dust storm period in Beijing. Science of the Total Environment, 345, 153-164, 2005.

27. Szaframiec, K. and Jedrychowski, W. : Spatial variability and trends in ambient air concentrations of metals in Cracow, Poland. International Journal of the Occupational Medicine and Environmental Health, 14, 261-265, 2001.

28. Freitas, M. C., Farinha, M. M., Ventura, M. G., Almeida, S. M., Reis, M. A. and Pacheco, A. M.: Gravimetric and chemical features of airborne PM10 AND PM2.5 in mainland Portugal. Environmental Monitoring and Assessment, 109, 81-95, 2005.

29. Karar, K., Gupta, A. K., Kumar, A. and Biswas, A. K. : Characterization and identification of the sources of chromium, zinc, lead, cadmium, nickel, manganese and iron in PM10 particulates at the two sites of Kolkata, India. Environmental Monitoring and Assessment, 120, 347-360, 2006.

30. Samara, C. and Voutsa, D. : Size distribution of airborne particulate matter and associated heavy metals in the roadside environment. Chemosphere 59, 1197-1206, 2005.

31. Cheng, M. T., Lin, Y. C., Chio, C. P., Wang, C. F. and Kuo, C. Y.: Characteristics of aerosols collected in central Taiwan during an Asian dust event in spring 2000. Chemosphere, 61, 1439-1450, 2005.

32. Chang, S., Fang, G., Chou, C. and Chen, W. : Source identifications of PM10 aerosols depending on hourly measurements of soluble components characterization among different events in Taipei Basin during spring season of 2004. Chemosphere, 65, 792-801, 2006.

33. Fang, G., Chang, C., Wu, Y., Lu, S., Fu, P., Chang, S., Cheng, C. and Yuen, W. : Concentration of atmospheric particulates during a dust storm period in central Taiwan, Taichung. Science of the Total 
Environment, 287, 141-145, 2002.

34. Kim, K. and Kim, M. : The effects of Asian dust on particulate matter fractionation in Seoul, Korea during spring 2001. Chemosphere, 51, 707-721,
2003.

35. Liu, C., Young, C. and Lee, Y. : Influence of Asian dust storms on air quality in Taiwan. Science of the Total Environment, 368, 884-897, 2006. 